Note

\section{Effects of Diets on the Concentration of Fructose-2,6-bisphosphate in Rat Liver}

\author{
Kazutaka MiyataKe, Toshiki Enomoto, \\ Kenichiro KaKiHara, Yuichi Kawano, \\ Yoshihisa NAKANO and \\ Shozaburo KITAOKA
}

\author{
Department of Agricultural Chemistry, \\ University of Osaka Prefecture, \\ Sakai, Osaka 591, Japan
}

Received June 18, 1986

Fructose-2,6-bisphosphate (Fru-2,6- $\mathrm{P}_{2}$ ), a metabolite first isolated as a liver phosphofructokinase (PFK, EC 2.7.1.11) activation factor, is now thought to play a central role in the hormonal regulation of glycolysis and gluconeogenesis in animal cells. ${ }^{1)}$ Despite the considerable interest in Fru-2,6- $\mathrm{P}_{2}$, very few experiments have been done in vivo to determine how Fru-2,6- $\mathrm{P}_{2}$ contributes to the regulation of carbohydrate metabolism. Therefore, we determined the concentration of Fru-2,6- $\mathrm{P}_{2}$ in the liver of rats that were fed on various diets.

Male rats (Jcl Wistar) were obtained from Clea Japan Inc., Tokyo, and feeds were from Wako Pure Chemicals, Osaka. Food and water were given ad libitum. The rats were kept in separate cages and were fed on a starch diet that comprised, by weight, $74 \%$ corn starch, $15 \%$ vitaminfree casein, $5 \%$ soy bean oil, $4 \%$ salt mixture, $1 \%$ vitamin mixture, $0.7 \%$ cellulose powder and $0.3 \%$ choline chloride. After 3 weeks, the rats were assigned to groups $(n=5)$ so that the average body weights and standard deviations of body weights were similar. One group of rats continued to receive the starch diet, the groups being fed on one of the following diets, which were different from the starch diet in the carbohydrate composition as indicated: sucrose diet (60\% sucrose and $14 \%$ corn starch), glucose diet (glucose $60 \%$ and $14 \%$ corn starch), fructose diet $(60 \%$ rructose and $14 \%$ corn starch), zein diet $(15 \%$ zein and $74 \%$ corn starch), and high-casein diet (79\% casein and 10\% corn starch). The rats were fed on the diets for one week. On the last day of the experiment, the animals were given food and, after two hours, they were anesthetized with sodium pentobarbital $(6.5 \mathrm{mg} / 100 \mathrm{~g}$ of body weight). Their livers were removed and frozen between alumiun dishes, which had been cooled in liquid nitrogen. The frozen livers were stored at $-80^{\circ} \mathrm{C}$. Some livers were processed according to the method of Hue et al. ${ }^{2}$ ) with slight modifications. Frozen liver (1 gram) was combined with $4 \mathrm{ml}$ of a buffer $(10 \mathrm{~mm}$ Tris-acetate at $\mathrm{pH} 8.5)$ and homogenized in a teflon glass homogenizer for $5 \mathrm{~min}$. The homogenate was transferred to centrifuge tubes, $5 \mathrm{ml}$ of acetone added and the mixture was placed in a water bath $\left(95^{\circ} \mathrm{C}\right)$ for $5 \mathrm{~min}$. The denatured protein was sedimented at $20,000 \times g$ for $10 \mathrm{~min}$. The supernatant was transfered again to a centrifuge tube, which contained $0.2 \mathrm{mg}$ (dry weight) of charcoal. The tubes were stirred for $30 \mathrm{~min}$ before the charcoal was sedimented at a $20,000 \times \dot{g}$ for $10 \mathrm{~min}$. An aliquot of this solution was used for Fru-2,6- $\mathrm{P}_{2}$ determination. Recovery of Fru-2,6- $\mathbf{P}_{2}$ from each tissue was estimated by adding a known amount of the compound to a duplicate samples of the tissues along with the homogenizing buffer. Fru-2,6- $\mathrm{P}_{2}$ was assayed by the method of Van Schaftingen et al. ${ }^{3)}$ based on the stimulation of potato pyrophosphate: D-fructose-6-phosphate 1-phosphotransferase (PFP, EC 2.7.1.90). Reagents were analytical grade of the highest purity available. Fru-6-P and Fru-2,6- $\mathrm{P}_{2}$ were obtained from Sigma, and auxiliary enzymes were purchased from Boehringer. The reaction mixture for the Fru-2,6- $\mathrm{P}_{2}$ assay contained, in a $1 \mathrm{ml}$ final volume, desalted coupling enzymes, 0.5 unit of aldolase (EC 4.1.2.13), 1 unit of glycerol-3-phosphate dehydrogenase (EC 1.1.1.8) and 1 unit of triosephosphate isomerase (EC 5.3.1.1), Trisacetate $(\mathrm{pH} 8.0,50 \mathrm{mM}), \mathrm{MgCl}_{2}(5 \mathrm{mM})$, tetrasodium EDTA (0.2 mM), NADH (0.2 mM), Fru-6-P ( $4 \mathrm{~mm})$, sodium pyrophosphate $(1 \mathrm{mM})$ and 5 munit of potato PFP. The concentration of Fru-2,6- $\mathrm{P}_{2}$ is expressed per $\mathrm{g}$ of weight of the liver. The recovery of authentic Fru-2,6- $\mathrm{P}_{2}$ after this procedures was $75 \sim 80 \%$.

The concentration of Fru-2,6- $\mathrm{P}_{2}$ in the livers from five rats that had been fed on a commercial diet was an average $7 \mathrm{nmol}$ per gram of liver, and this value agrees with those reported for rat liver by other researchers. ${ }^{4 \sim 7)}$ Diets containing high protein favor hepatic gluconeogenesis, while those high in carbohydrates depress gluconeogenesis and promote glycolysis and lipogenesis. Therefore, we expected to find a higher concentration of Fru-2,6- $\mathrm{P}_{2}$ in the liver of rats fed on the high-carbohydrate diets than in the liver of rats fed on the high-protein diets. The high carbohydrate diets produced relatively high concentrations of Fru2,6- $\mathrm{P}_{2}$ (Table I), which based on in vitro studies, should enhance glycolysis by activating $\mathrm{PFK}^{7 \sim 9)}$ and inhibiting fructose-1,6-bisphosphatase (FBPase, EC 3.1.3.11). ${ }^{10,11)}$ The concentration of Fru-2,6- $\mathrm{P}_{2}$ in the liver of rats fed on a high casein (gluconeogenic) diet was very low; the decrease in the concentration of this compound relieves FBPase activity through the inhibition by Fru-2,6- $\mathrm{P}_{2}$ and promotes gluconeogenesis. No difference was observed in the hepatic Fru-2,6- $\mathrm{P}_{2}$ concentration among the rats fed on different types of carbohydrate, except for fructose (Table I). In rats fed on the high-fructose diet, the Fru-2,6$\mathrm{P}_{2}$ concentration was somewhat decreased, agreeing with the results of experiments with hepatocytes. ${ }^{2)}$ The physiological importance of Fru-2,6- $\mathrm{P}_{2}$ as a regulator of PEK is thought to be due to its switching action on the glucose metabolism between glycolysis and gluconeogenesis. This is supported by the fact that glucagon, which promotes 
Table I. EfFect of Diets on the Concentration OF FRU-2,6-P ${ }_{2}$ IN RAT LIVER

\begin{tabular}{lc}
\hline \multicolumn{1}{c}{ Diet } & Fru-2,6-P $(\mathrm{nmol} / \mathrm{g}$ rat liver $)$ \\
\hline Glucose & $9.2 \pm 2.5$ \\
Sucrose & $7.1 \pm 1.9$ \\
Fructose & $3.7 \pm 0.9^{*}$ \\
Starch & $6.5 \pm 1.5$ \\
Zein & $1.7 \pm 0.6^{*}$ \\
High casein & $0.8 \pm 0.2^{*}$ \\
\hline
\end{tabular}

The values are means $\pm S E M$ for 5 rats.

* Significantly different from the starch-fed group, using $t$-test analysis; $p<0.01$.

hepatic gluconeogenesis, rapidly decreases the concentration of Fru-2.6- $\mathrm{P}_{2}$ in rat hepatocytes, ${ }^{12,13)}$ and that with a high-casein diet (Table I), starvation and diabetes depress its concentration in rat liver ${ }^{4,5}$ and in mouse liver. ${ }^{14)}$ The zein diet also lowered the hepatic concentration of Fru-2,6- $\mathrm{P}_{2}$, probably due to the enhanced gluconeogenesis caused by the amino acids after hydrolysis.

The regulation of glycolysis and gluconeogenesis by Fru-2,6- $\mathrm{P}_{2}$ is achieved through modification of the target enzymes; in the case of glycolysis, it is performed by activation of PFK and inhibition of FBPase. ${ }^{1)}$ Fru-2,6- $\mathrm{P}_{2}$ also appears to mediate the hormonal effects on these in animals. ${ }^{1)}$ The present finding of the change of Fru-2,6- $\mathrm{P}_{2}$ levels in rat liver due to diets is very interesting, and the result suggests that diets can also regulate not only hepatic glycolysis but also gluconeogensis through Fru-2,6- $\mathrm{P}_{2}$. However, the regulation mechanism of Fru-2,6- $\mathrm{P}_{2}$ by diets has not yet been elucidated.

\section{REFERENCES}

1) H. G. Hers and L. Hue, Ann. Rev. Biochem., 52, 1161 (1983).

2) L. Hue, P. F. Blackmore, H. Shikman, A. RobinsonStein and J. H. Exton, J. Biol. Chem., 257, 4308 (1982).

3) E. Van Schaftingen, L. Hue and H. G. Hers, Biochem. J., 192, 897 (1980).

4) M. Kuwajima and K. Uyeda, Biochem. Biophys. Res. Commun., 104, 84 (1982).

5) P. Neely, M. R. El-Maghrabi, S. J. Pilkis and T. H. Claus, Diabetes, 30, 1062 (1981).

6) J. Sommercorn and R. A. Freeland, J. Nutr., 114, 1462 (1984).

7) S. J. Pilkis, M. R. Maghrabi, J. Pilkis, T. H. Claus and D. A. Cumming, J. Biol. Chem., 256, 3171 (1981).

8) E. Van Schaftingen, M. F. Jett, L. Hue and H. G. Hers, Proc. Natl. Acad. Sci. U.S.A., 78, 3483 (1981).

9) K. Uyeda, E. Furuya and A. D. Sherry, J. Biol. Chem., 256, 8679 (1981).

10) S. J. Pilkis, M. R. Maghrabi, J. Pilkis and T. H. Claus, J. Biol. Chem., 256, 3619 (1981).

11) E. Van Schaftingen and H. G. Hers, Proc. Natl. Acad. Sci. U.S.A., 78, 2861 (1981).

12) C. S. Richards and K. Uyeda, J. Biol. Chem., 257, 8854 (1982).

13) T. H. Claus, J. Schlumpf, J. Pilkis, R. A. Johnson and S. J. Pilkis, Biochem. Biophys. Res. Commun., 98, 359 (1981).

14) S. Sumi, I. Mineo, N. Kono, T. Shimizu, K. Nonaka and S. Tarui, Biochem. Biophys. Res. Commun., 120, 103 (1984). 